\title{
Generator DC 12 VOLT dengan Kapasitas 270 Watt untuk PLTMH Dijalan Bintara Sungai Duren Kecamatan Jambi Luar Kota Kabupaten Muara Jambi
}

\author{
Myson $^{1}$, Anwar Aritonang ${ }^{2}$ \\ ${ }^{1,2}$ Teknik Listrik, Fakultas Teknik, Universitas Batanghari \\ Correspondence email: myson_ade1@yahoo.com; erikajulianti5@gmail.com
}

\begin{abstract}
Abstrak. Kebutuhan energi listrik meningkat setiap tahun, sehingga pemanfaatan sumber energy terbarukan diperlukan sebagai sumber energi alternatif. Untuk memproleh daya yang besar maka dipilih generator DC magnet permanen, generator magnet permanen mempunyai efisiensi baik pada putaran rendah dan turbin cros flow dapat bekerja pada debit yang tidak terlalu tinggi.Generator DC digunakan sebagai pembangkit PLTMH dengan skala kecil yang meggunakan tenaga air sebagai penggeraknya. Pembangkit Mikrohidro skala kecil ini bisa menghasilkan daya sebesar 270 watt dengan tegangan yang keluar dari generator 12-18 Volt.
\end{abstract}

Kata Kunci: Pemanfaatan Generator Magnet Permanet 12 V; Rotor,Stator,Pulley

Abstract. Electricity energy needs are increased annually, so utilization of renewable energy sources is required as an alternative source of energy. To Progood Power then selected DC Permanent Magnet generator, permanent magnet generator has good efficiency in low round and the Cros flow turbine can work on not too high discharge. The DC Generator is used as a small scale PLTMH plant that uses hydropower as its movement. This small-scale Microhydro generator can generate 270 watts of power with the voltage coming out of the 12-18 Volt generator.

Keywords: utilization of the magnetic Generator Permanet 12 V; Rotor, Stator, Pulley

\section{PENDAHULUAN}

Mikrohidro atau yang dimaksud dengan Pembangkit Listrik Tenaga Mikrohidro (PLTMH), adalah suatu pembangkit listrik skala kecil yang menggunakan tenaga air sebagai tenaga penggeraknya seperti, saluran irigasi, sungai atau air terjun alam dengan cara memanfaatkan tinggi terjunan (head) dan jumlah debit air. Mikrohidro merupakan sebuah istilah yang terdiri dari kata mikro yang berarti kecil dan hidro yang berarti air. Secara teknis, mikrohidro memiliki tiga komponen utama yaitu air (sebagai sumber energi), turbin dan generator

Mikrohidro mendapatkan energi dari aliran air yang memiliki perbedaan ketinggian tertentu. Pada dasarnya, mikrohidro memanfaatkan energi potensial jatuhan air (head). Semakin tinggi jatuhan air maka semakin besar energi potensial air yang dapat diubah menjadi energi listrik [1].

Di samping faktor geografis (tata letak sungai), tinggi jatuhan air dapat pula diperoleh dengan membendung aliran air sehingga permukaan air menjadi tinggi. Air dialirkan melalui sebuah pipa pesat kedalam rumah pembangkit yang pada umumnya dibagun di bagian tepi sungai untuk menggerakkan turbin atau kincir air mikrohidro. Energi mekanik yang berasal dari putaran poros turbin akan diubah menjadi energi listrik oleh sebuah generator.[1]

PLTMh baiknya digunakan pada daerah yang mempunyai syarat sebagai berikut: potensi energi air yang melimpah dan terdapat beda tinggi air di suatu wilayah atau alur sungai, baik berupa terjunan, alur sungai yang curam atau aliran air sungai yang bisa dibendung, maka disitu dapat dibangun PLTMH.

Pembangkitan listrik mikrohidro adalah pembangkitan listrik dihasilkan oleh generator listrik DC atau AC[2]. Mikrohidro hanyalah sebuah istilah. Mikro artinya kecil sedangkan Hidro artinya air. Dalam prakteknya istilah ini tidak merupakan sesuatu yang baku namun Mikro Hidro, pasti menggunakan air sebagai sumber energinya [3].

Pembangkit Listrik Tenaga Mikro Hidro (PLTMH), juga mempunyai suatu kelebihan dalam hal biaya operasi yang rendah jika dibandingkan dengan Pembangkit Listrik seperti Pembangkit Listrik Tenaga Diesel (PLTD), Pembangkit Listrik Tenaga Uap (PLTU) dan Pembangkit Listrik lainnya karena Mikro Hidro memanfaatkan energi sumber daya alam yang dapat diperbarui, yaitu sumber daya air. Dengan ukurannya yang kecil penerapan Mikro Hidro relatif mudah dan tidak merusak lingkungan. Rentang penggunaannya cukup luas, terutama untuk menggerakkan peralatan atau mesin-mesin yang tidak memerlukan persyaratan stabilitas tegangan yang akurat [3].

PLTMH adalah termasuk dalam kategori PLTA (Pembangkit Listrik Tenaga Air), karena prinsip kerja dan cara pembuatan PLTMH tersebut sama dengan PLTA umumnya. PLTMH juga dapat dikatakan sebagai PLTA berkapasitas kecil. Akhir - akhir ini di dunia, termasuk negara-negara maju, banyak terdapat pembangunan PLTA berkapasitas kecil. Pembagian 
PLTA dengan kapasitas kecil pada umumnya adalah sebagai berikut:

- PLTA Mikro < $100 \mathrm{~kW}$

- PLTA Mini 100 - $999 \mathrm{~kW}$

- PLTA Kecil 1000 - 10000 kW

\section{Tujuan Umum Pembangkit Tenaga Mikrohidro}

Pembangkitan listrik mikrohidro adalah pembangkitan listrik dihasilkan oleh generator listrik DC atau AC[2]. ]Mikrohidro hanyalah sebuah istilah. Mikro artinya kecil sedangkan Hidro artinya air. Dalam prakteknya istilah ini tidak merupakan sesuatu yang baku namun Mikro Hidro, pasti menggunakan air sebagai sumber energinya [3].

Beberapa keuntungan yang terdapat pada pembangkit listrik tenaga listrik mikrohidro adalah sebagai berikut [4.]

1. Dibandingkan dengan pembangkit listrik jenis yang lain, PLTMH ini cukup murah karena menggunakan energi alam.

2. Memiliki konstruksi yang sederhana dan dapat dioperasikan di daerah terpencil dengan tenaga terampil penduduk daerah setempat dengan sedikit latihan.

3. Tidak menimbulkan pencemaran.

4. Dapat dipadukan dengan program lainnya seperti irigasi dan perikanan.

5. Dapat mendorong masyarakat1 agar dapat menjaga kelestarian hutan sehingga ketersediaan air terjamin.

\section{Prinsip Kerja Pembangkit Listrik Tenaga Mikrohidro}

Prinsip dasar mikrohidro adalah memanfaatkan energi potensial yang dimiliki oleh aliran air pada jarak ketinggian tertentu dari tempat instalasi pembangkit listrik.Sebuah skema mikrohidro memerlukan dua hal yaitu, debit air dan ketinggian jatuh (head) untuk menghasilkan tenaga yang dapat dimanfaatkan.

Daya yang masuk (Pgross) merupakan penjumlahan dari daya yang dihasilkan (Pnet) ditambah dengan faktor kehilangan energi (loss) dalam bentuk suara atau panas. [4].

Daya yang dihasilkan merupakan perkalian dari daya yang masuk dikalikan dengan efisiensi konversi (Eo).

\section{Pnet $=$ Pgross $\times$ Eo $\mathrm{kW}$}

Daya kotor adalah head kotor (Hgross) yang dikalikan dengan debit air (Q) dan juga dikalikan dengan sebuah faktor gravitasi $(\mathrm{g}=9.8)$, sehingga persamaan dasar dari pembangkit listrik adalah :

Pnet $=\mathrm{g} \times$ Hgross $\times \mathrm{Q} \times$ Eo $\mathrm{kW}$

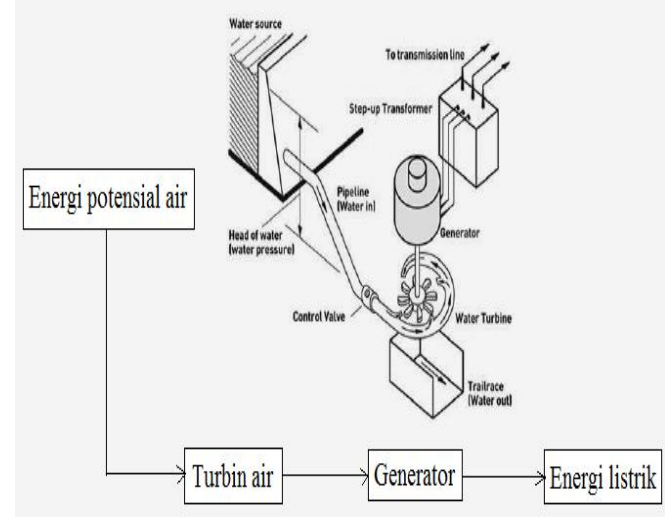

Gambar 1. Prinsip Kerja PLTMH

\section{Potensi Tenaga Air}

Dalam PLTA, potensi air dikonversikan menjadi tenaga listrik. Mula-mula potensi tenaga air dikonversi menjadi tenaga mekanik untuk memutar turbin, kemudian turbin akan memutara generator yang dapat menghasilkan listrik [1].

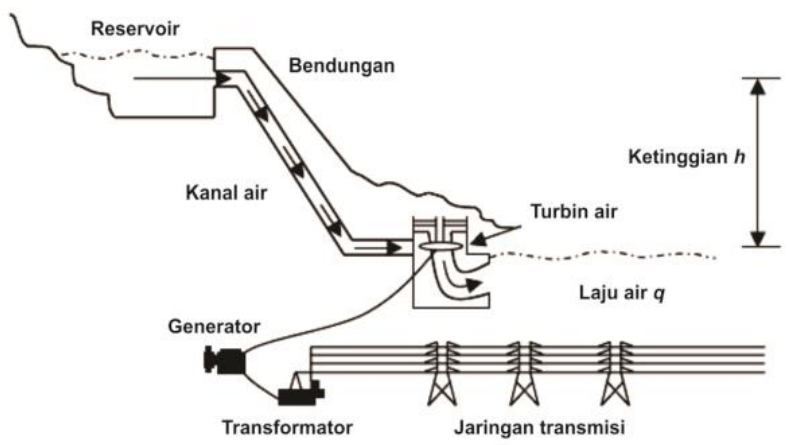

Gambar 2. Prinsip Kerja PLTA

Adapun persamaan atas Daya yang dibangkitkan generator yang diputar oleh Turbin Air adalah:

$\mathrm{P}=\mathrm{k} \cdot \eta \cdot \mathrm{H} \cdot \mathrm{q} \cdot[\mathrm{kW}]$

dimana:

$\mathbf{P} \quad=$ daya $[\mathrm{kW}]$

$\mathbf{H} \quad$ = tinggi air terjun (meter)

q $\quad$ debit air $\left[\mathrm{m}^{3} /\right.$ detik $]$

$\boldsymbol{\eta}=$ efesiensi turbnin bersama generator

k $\quad=$ konstanta

Konstanta (k) dihitung berdasarkan pengertian bahwa 1 daya kuda $=75 \mathrm{kgm} /$ detik dan 1 daya kuda $=$ $0,736 \mathrm{~kW}$ sehingga apabila $\mathrm{P}$ ingin dinyatakan dalam $\mathrm{kW}$, sedangkan tinggi air terjun $(\mathrm{H})$ dinyatakan dalam meter dan debit air (q) dalam $\mathrm{m}^{3} /$ detik, maka:

Konstans $\mathrm{k}$

$=\frac{m^{3}}{d e t} \times \frac{1000 \mathrm{~kg}}{m^{3}} \times m \times \frac{1 \mathrm{dk}}{75 \frac{\mathrm{kgm}}{\mathrm{det}}} \times 0,736 \frac{\mathrm{kw}}{\mathrm{dk}}=9,813$

$=9,8$ 
Myson dan Anwar Aritonang, Generator DC 12 VOLT dengan Kapasitas 270 Watt untuk PLTMH Dijalan Bintara Sungai Duren Kecamatan Jambi Luar Kota Kabupaten Muara Jambi

\section{Generator}

Generator adalah suatu sistem yang menghasilkan tenaga listrik dengan masukan tenaga mekanik. Jadi disini generator berfungsi untuk mengubah tenaga mekanik menjadi tenaga listrik yang mempunyai prinsip kerja sebagai berikut: [5]

Rumus perhitungan generator

$\mathbf{P}=\mathbf{V}$.I

$\mathbf{I}=\mathbf{P} / \mathbf{V}$

Keterangan

$\mathbf{P} \quad=$ Daya $($ Watt $)$

$\mathbf{V} \quad=$ Arus

I = Tegangan (Volt)

\section{METODE}

\section{Tempat dan Waktu}

Perancangan alat di lakukan di benkel fakultas teknik listrik universitas batanghari jambi dan ditempat.

\section{Diagram Alur}

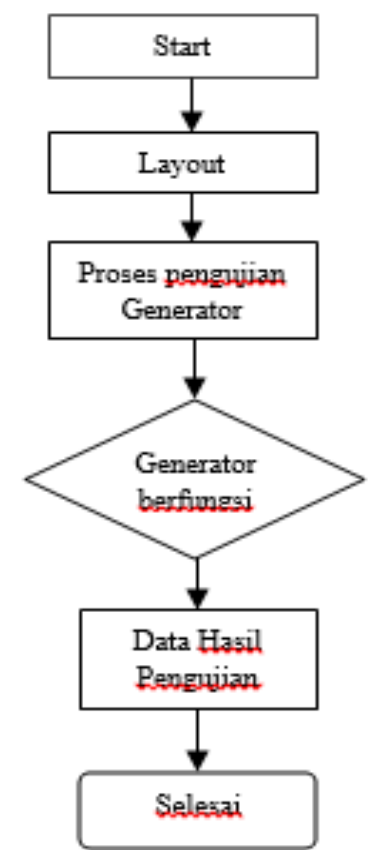

Gambar 3. Alur Bagan Proses

\section{HASIL DAN PEMBAHASAN}

Layout

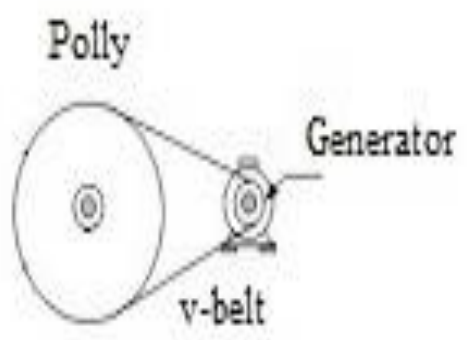

Gambar 4. Penempatan Generator

\section{Layout PLTMH}

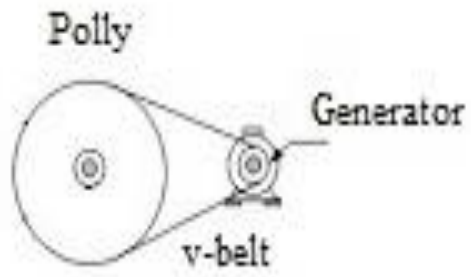

Gambar 5. Perencanaan Generator Untuk PLTMH

Keterangan:

Disini kita menggunakan Generator DC 12-18 Volt , 15 Amper Dengan type Generator Permanen Megnet

Spesifikasi:

Non Gerabox

Speed : 500-1000 Rpm

Output : DC 12-18 Volt

Arus $\quad: 15$ Amper

Dimensi Body : Panjang 10,5 $\mathrm{Cm}$ x 8,5 Cm

\section{Penempatan Generator}

Generator Diletakan di atas meja yang sudah bentuk dari plat besi. Pembuatan clam befungsi untuk menahan generator agar tidak mudah goyang karna tarikan V-belt yang terikat dari Polly Turbin, ukuran polly yang digunakan generator 2 inc dan untuk turbin 11 inc dengan panjang V-belt $74 \mathrm{~cm}$.

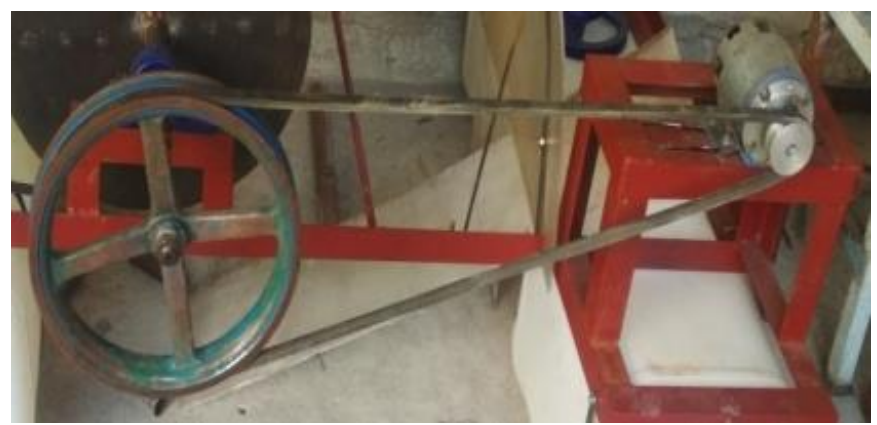

Gambar 6. Penempatan Generator Untuk PLTMH

\section{Hasil Pengujian \\ Pengujian Generator \\ Tanpa Beban}

Pengujian yang dilakukan bertujuan untuk menguji keluaran Generator pada saat tidak ada beban sehingga akan terlihat karakteristik murni dari keluaran Generator. Pengujian ini dilakukan dengan variasi putaran Generator.

Tabel 1. Pengujian Tanpa beban

\begin{tabular}{cccc}
\hline No & Head & Rpm & $\begin{array}{c}\text { Tegangan Output } \\
\text { Generator }\end{array}$ \\
\hline 1 & $20 \mathrm{~cm}$ & 540 & $12 \mathrm{~V}$ \\
2 & $34 \mathrm{~cm}$ & 642 & $14 \mathrm{~V}$ \\
3 & $51 \mathrm{~cm}$ & 790 & $16 \mathrm{~V}$ \\
\hline
\end{tabular}


Dari pengujian yang dilakukan diperoleh tegangan Output generator seperti tabel 4.1 tabel ini menunjukkan semakin besar putaran generator maka semakin besar tegangan yang di proleh.

\section{Pengujian Tanpa Beban}

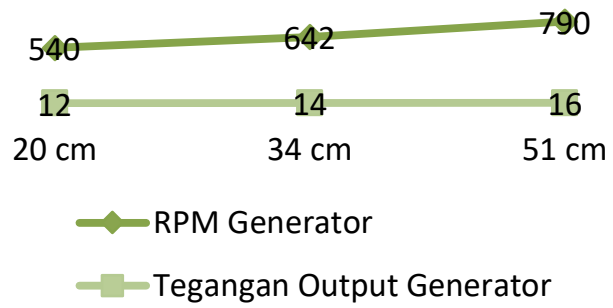

Gambar 7. Grafik Hubungan Putaran Generator Terhadap Tegangan

Pada Gambar diatas menunjukkan bahwa kecepatan Generator 540 Rpm dengan tegangan outpu DC 12 Volt. Pada kecepatan 790 Rpm Tegangan Output DC 16 Volt, maka semakin tinggi putaran rotor (Rpm) maka semakin tinggi outpunya. Tengangan Output merupakan keluaran dari Generator.

\section{Berbeban}

Pengujian yang di lakukan pada generator DC adalah pengujian berbeban hasil pengujian adalah sebagai berikut:

Tabel 2. Pengujian Generator Berbeban

\begin{tabular}{llllll}
\hline No & Head & Rpm & Daya Lampu & Arus & Tegangan \\
\hline 1 & $20 \mathrm{~cm}$ & 540 & $100 \mathrm{~W}$ & 8,9 & $11,2 \mathrm{~V}$ \\
2 & $34 \mathrm{~cm}$ & 642 & $100 \mathrm{~W}$ & 7,6 & $13,1 \mathrm{~V}$ \\
3 & $51 \mathrm{~cm}$ & 790 & $100 \mathrm{~W}$ & 6,4 & $15,5 \mathrm{~V}$ \\
\hline
\end{tabular}

Pengujian dilakukan dengan menentukan daya lampu yang akan digunakan sebagai beban generator. Pembebanan 100 watt yang diberikan mengakibatkan penurunan tegangan output generator sehingga arus yang mengalir semakin rendah, Nilai arus yang mengalir dipengaruhi dengan oleh tegangan nya. Nilai tengannya ini lah yang terkait dengan putaran Generator.

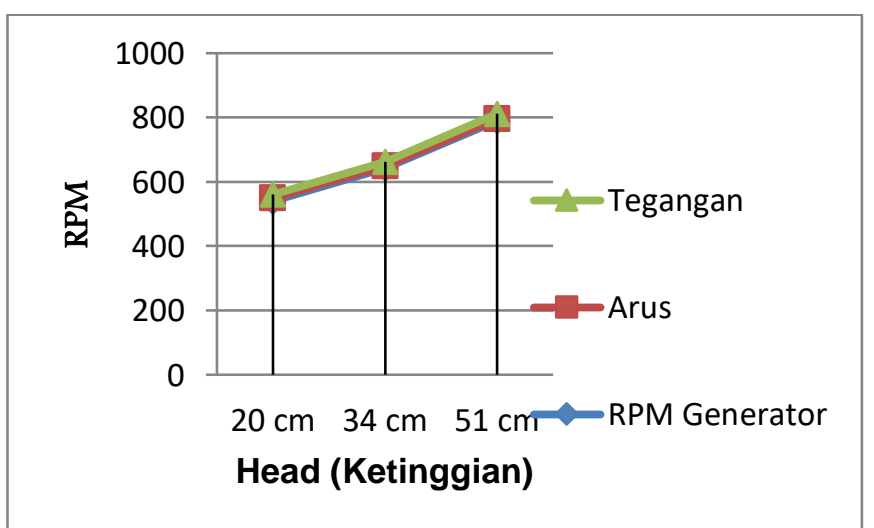

Gambar 8. Grafik Daya Tehadap Tegangan dan Arus
Pada Gambar diatas Pada saat dibebani 100 watt tegangan yang dihasilkan 11,2 Volt dengan arus yang mengalir 8,9 A dengan putaran $540 \mathrm{Rpm}$. Ketika diberikan beban 100 watt tegangan yang dihasilkan adalah 13,1 Volt dengan Arus yang mengalir 7,6 A dengan kecepatan 642 Rpm. Dan ketika dibebani 100 watt dengan tegangan 15,5 Volt dengan arus yang mengalir $6,4 \mathrm{~A}$

\section{SIMPULAN}

Pemanfaatan Generator DC untuk pembangkit mikrohidro (PLTMH) dengan memvariasikan hasil pengujian tanpa beban. Ketinggian (Head), RPM Generator dan Tegangan Output Generator, maka di dapat hasil pengujian sebagai berikut:

Tabel 3. Pengujian Tanpa beban

\begin{tabular}{cccc}
\hline $\begin{array}{c}\text { N } \\
\text { o }\end{array}$ & Head & Rpm & $\begin{array}{c}\text { Tegangan } \\
\text { Output } \\
\text { Generator }\end{array}$ \\
\hline 1 & $20 \mathrm{~cm}$ & 540 & $12 \mathrm{~V}$ \\
2 & $34 \mathrm{~cm}$ & 642 & $14 \mathrm{~V}$ \\
3 & $51 \mathrm{~cm}$ & 790 & $16 \mathrm{~V}$ \\
\hline
\end{tabular}

Tabel ini menunjuk kan semakin besar putaran generator maka semakin besar tegangan yang di proleh, hubungan antara putaran dan tegangan output dapat dilihat pada tabel 3 .

Pengujian berbeban ini dilakuakn dengan menentukan daya lampu yang akan digunakan sebagai beban generator. Hasil pengujian adalah sebagai berikut:

Tabel 4. Pengujian Generator Berbeban

\begin{tabular}{llllll}
\hline No & Head & Rpm & Daya Lampu & Arus & Tegangan \\
\hline 1 & $20 \mathrm{~cm}$ & 540 & $100 \mathrm{~W}$ & 8,9 & $11,2 \mathrm{~V}$ \\
2 & $34 \mathrm{~cm}$ & 642 & $100 \mathrm{~W}$ & 7,6 & $13,1 \mathrm{~V}$ \\
3 & $51 \mathrm{~cm}$ & 790 & $100 \mathrm{~W}$ & 6,4 & $15,5 \mathrm{~V}$ \\
\hline
\end{tabular}

Pembebanan yang diberikan mengakibatkan penurunan tegangan output generator sehingga arus yang mengalir semakin tinggi, Nilai arus yang mengalir dipengaruhi dengan oleh tegangan nya. Nilai tengannya ini lah yang terkait dengan putaran Generator.

\section{Saran}

1. Saat melakukan survei lapangan persiapkan alat ukur yang memadai untuk mendukung pengambilan data yang tepat.

2. Pemanfaatan PLTMH dapat menjadi sarana pembelajaran yang bagus untuk masyarakat oleh karna PLTMH menafaatkan energi lingkungan sekitar untuk mencukupi kebutuhan listrik.

3. Pemanfaatan generator DC untuk PLTMH belum sempurna sehingga butuh perbaikan agar pemanfaatan generator untuk pembangkit PLTMH bekerja dengan baik 


\section{DAFTAR PUSTAKA}

[1] Jack, Fritz.1984, Small and Mini Hydropower System, McGraw-Hill, New York,.

[2] Djiteng Marsudi 2005 Pembangkitan Energi Listrik, Balai Penerbit Humas ISTN Bhumi Serengseng Indah.

[3]https://www.kajianpustaka.com/2016/10/pembangkitlistrik-tenaga-mikro-hidro.html

[4] https://insyaansori.blogspot.com

[5] http://elektro-unimal.blogspot.com/2013/05/jenisgenerator-dc.html

[6] Ardinathasanjaya, 2017/04/28, Generator AC and DC, Semarang 